\title{
Student-supervisor interaction problems in joint research activity
}

\author{
O.A. Selivanova ${ }^{1 *}$, O.I. Dubrovina ${ }^{2}$ and O.N. Rodina ${ }^{3}$ \\ ${ }^{1}$ Tyumen State University, Tyumen, Russia \\ 2 Tyumen State University, Tyumen, Russia \\ ${ }^{3}$ Industrial university of Tyumen, Tyumen, Russia
}

\begin{abstract}
Growing interest in improving the quality of student's research activity in higher education has led to an emphasis on student-supervisor interaction in joint research activity. The study presented here was carried out in Tyumen State University, Tyumen, Russia. The participants were 30 supervisors and 60 students from the Pedagogical Institute. The study defined student and supervisor interaction problems and characterized the ways of student-supervisor interaction that reduce student's motivation for a creative approach to writing research work when student's research work is perceived as (1) supervisor's burden, (2) a source of supervisor's innovative ideas, (3) a source of additional information or (4) a source of primary information processing for supervisor's scientific work. Implications are given to prevent ineffective ways of student-supervisor interaction and improve the quality of student's research training in multilevel university education.
\end{abstract}

\section{A problem statement}

One of the key goals of the project «Science» until 2024 is to ensure collaboration between Russian and Foreign leading researchers and young promising ones in the Russian Federation. The share of researchers under the age of 39 in the total number of Russian researchers should be $50,1 \%$ by 2024 . According to the 'Concept for Russian education modernization for the period until 2020' and the Law on 'Higher and Postgraduate Professional Education', one of the priorities of educational policy is a radical improvement of the vocational education system aimed at training highly qualified specialists.

In this regard, one of the urgent directions of university educational process development is to prepare students and graduate students for research activity. Improving the quality of student's higher degree research has been one of the most discussed issues for several decades. It's no secret that truly deep and interesting research based on student's profound practical activity is very rare in psychological and pedagogical practice. The accessibility of electronic information sources and, unfortunately, innumerable plagiarism

\footnotetext{
* Corresponding author: ipcs-profped@yandex.ru
} 
in the modern educational process turn the writing of a student's thesis work into a routine compilation, often devoid of any sense of moral decency. Under these conditions, it is very difficult to talk about cultivation of a research competence, a researcher's position, and motivation to search.

Universities face challenges due to the nature and structure of information presented in electronic environment: formalized operations of 'juggling' with fragments of text minimize the need for thoughtful analysis of the content, its comprehension and building own ideas about the phenomenon being studied without which it is impossible to create any author's text, not to mention a piece of scientific research. There is another problem associated with this: if in the era of printed texts the student's algorithm actions and operations (for example, design requirements for work, its structure, etc.) contributed to systematization of received information, and an attempt to perform a piece of scientific work in accordance with the methodology of a particular scientific field (in our case, psychology or pedagogy) gradually cultivated a researcher's position, then under modern conditions students perceive the logic of organizing and conducting research work as a template. It is not uncommon when the paragraph titles of research work do not correspond at all with their contents, and the contents of the work parts are not logically related with each other. And if earlier, it indicated a low intellectual potential of the author, now it shows a formalized distribution of downloaded text fragments according to a given structure of research work.

Numerous scientific studies have indicated the need for parity in student-supervisor interaction and cooperation in joint knowledge of scientific truth, search for solutions to scientific problems, the development of new approaches. Ideal interaction is that in which the supervisor acts as a mentor, a tutor, a leader of a scientific school. It is worth recognizing that in educational practice of pedagogical university the above-mentioned roles are more likely a rarity than a norm. The problem of low level student's motivation to study at university as a whole and to conduct research in particular is widely known and described in great details.

An attempt to find solutions to this problem makes it necessary to analyze reasons that reduce student's motivation to be creative in research in general and in thesis research in particular. The purpose of the paper is to characterize student-supervisor interaction problems in joint research activity.

A considerable amount of literature has been published on psychological and pedagogical aspects of student and supervisor's joint research activity. But in the context of continuous education development, the issues related to student and supervisor's joint research activity acquire much greater significance. Educational trajectories suggest the transition from the one-sided impact of the education system (through curricula) to an individual approach based on student and supervisor's joint activity. There have been a number of studies that investigate the organization of student-supervisor interaction through a research competence. Barnett and Muth consider university student's research work as a unique level of the success of university's educational activities [1].

Gullbekk and Byström describe the phenomenon of a research competence and the process of its formation at university [2]. A number of researchers have considered the development of research competence's components through the inclusion of students in academic writing practice for publications and noted the difficulties of their integration into an international academic community [3-9]. Morton, Storch, and Thompson define the students' problems in meeting the written assignment requirements and reporting research results beyond formal interaction [10]. Santos and Cechinel characterize remote interaction through online communication while organizing joint research activity [11].

Recent studies have identified the role of students' personal qualities and their strategies in the formation of a research competence, the influence of students' independence level 
and self-organization on the quality of the formation of research competencies in the learning process [12], the strategies of Iranian students involving in interaction both with supervisors and members of various academic communities through professional online networks, a crucial role of feedback from student-supervisor interaction and the quality of established relationships [13], the problems arising in the student-supervisor relationships at the beginning of research and the influence of student-supervisor contacts on further research work [14].

Joint research activity is considered as a multi-factor process, and a systematic approach to the problem of organizing student-supervisor interaction should be developed. There is an idea of variables that can be used to develop individual programs to build studentsupervisor interaction. An interaction model can be affected by the use of a wide range of approaches to building joint research activity, based on one's experience; the recognition of relations with students as a great importance; the understanding of responsibility for personal development during student's research activity. There is a matter of great concern for creating programs for supervisor's development [9]. There is also an increasing interest in student-supervisor interaction in the context of joint research activity in Russia. The researchers offer the description of models for formation and assessment of a research competence; consider a student's thesis work as student-supervisor research activity [1520]. The supervisor in the course of such activity has the opportunity to annually change the interaction scenario, refine the content of meetings, and set new tasks to improve the quality of interaction. This way the supervisor is engaged in self-education. For the student it is more important to recognize the authorship of his/her piece of work, the possibility of self-realization then the implementation of tasks received from the supervisor. Koshkina considers the possibility of developing a student's research competence through scientific research seminars and external (outside the institution) research projects [20]. Zakirova characterizes the content and structure of the methodological apparatus of scientific research related to education. She outlines the directions for the implementation of multiangle reflection in research activity that allows supervisors to increase the effectiveness and meaningfulness of mentoring activity [16].

Special attention has been given to the importance of creating special environment for the formation of a research competence and supporting motivation. Gebekova considers the formation of a creative personality through the motivation of student's cognitive and scientific activity. She suggests developing students' creative groups, taking into account scientific interests, possibilities and experience in scientific work; equipping students with a scientific research base and the methodology of scientific work; creating situations of success for implementing scientific results in practice; encouraging creative activity in solving scientific problems. Gebekova concludes that student's research activity under supervision forms general and professional competencies in the subject field, in the field of information technology, and in design and analytical activities [17].

Aminov and Sharapova present an idea that any university should provide students with access to information resources for research activity, modern means of information technology for information processing, storage and accounting during research activity organization. The authors write that the use of modern information technologies allows students to get a large amount of ready-made knowledge, but also to develop students' intellectual ability, creative skills, and skills to independently acquire new knowledge and to work with various information sources [21].

There have been a number of studies related to online organization of student's research activity with the use of Internet technologies [17, 22-24]. Topolskiy points out that in the modern world successful participation at a scientific conference is impossible without a multimedia presentation, which requires a set of necessary skills. Also, the author sees opportunities for development of independent student work when accessing the Internet, 
which should be a separate task for supervisors [22]. In his studies, Gospodarik concludes that information and communication technologies have become a powerful factor in the modern education system, while scientific and pedagogical communities pay insufficient attention to the phenomenon of students' immersion on the Internet. According to Gospodarik, the basic element that creates the conditions for development of student's educational and research activity is the formation of information subject environment for a discipline (a group of disciplines). There are three types of information subject environment focused on information presentation (electronic libraries), on independent student's work organization, including research activity and mixed type information subject environment. He considers student's publications to be the first step in student's research projects in the context of information subject environment. A great platform for such publications can become, for example, a scientific blog [24]. In addition, Belyakova and Zakharova distinguish the types of educational contents that students use, make up the rating and demonstrate the ways how students use different resources of information and education environment [25]. However, some researchers point to the inevitable problems of studentsupervisor interaction under modern conditions. Zakharova describes the destructive influence of the use of Internet sources [23]. Strokova underlines a lack of readiness of many graduate students to organize and conduct independent scientific search, the inability to use the elements of methodological apparatus and the weak skills to create scientific texts [26].

Researchers note that modern supervisors must satisfy new requirements. Students have new expectations, interacting with them. Now supervisors should perform a wide range of roles. According to Arzhilovskaya and Chumakova, a supervisor of the XXI century must be an educator transferring knowledge, stimulating student's activity, forming skills, a mentor taking care of comprehensive development of student's personality, forming professional and psychological qualities, a scientist engaged in scientific research in the field of taught discipline, a manager organizing classrooms, stimulating and controlling students' independent work. Under these conditions, the technology for organizing interaction in the innovative research process includes focused joint research activity with a sequence of the following steps: 1) an orientation step at which students are motivated and oriented towards interaction in research activity, 2) a coordination step at which students and supervisors adopt roles, organize interaction on principles of parity 3) a cooperation step at which they interact using a common strategy for joint research activity [27]. According to Frolov, the technology of organizing student-supervisor interaction (cooperation) should be built on from coordination to cooperation with the leading role of supervisors [19]. Khojaliev also points out that the supervisor should adopt several main roles. The supervisor organizes interaction in a particular area of information environment. As an expert, the supervisor sets out text material, answers students' questions, tracks the results of the process, etc. As an organizer, the supervisor establishes interaction with students in social and physical environment (divides students into subgroups, encourages them to independently collect data, coordinates tasks fulfillment, etc.). As a consultant, the supervisor turns to student's professional experience, helps seek solutions to already posed problems, and sets new ones [28]. Andreeva, Selivanova, and Vasilieva pay attention to assessing the effectiveness of student-supervisor interpersonal interaction and its influence on research competence formation [29].

In general, literature review shows that joint research activity at university involves a system that includes the preparation of supervisors and provides special conditions for educational environment, taking into account student's personality and constantly changing requirements for organizing and conducting research. The most important key condition for the implementation of the system is the quality of student-supervisor interpersonal interaction in joint research activity. The review showed that recent studies on joint 
research activity have paid attention to the external factors of the process: the inclusion of students in academic writing practice, the description of a research competence, the difficulties of students' integration into an international academic community, the problems of requirements meeting, student's personal qualities, and joint research activity individual programs. At the same time, it is not less important to study internal factors such as supervisor's perception on building interaction with students. The study aims to identify these factors.

\subsection{The objective of the work}

The study of student-supervisor interaction problems in joint research activity was carried out in Tyumen State University, the Pedagogical Institute, Tyumen, Russia. The participants were thirty supervisors, aged 25-50, teaching at psychological and pedagogical programs, twenty students from the first year Bachelor's degree course, twenty students from the first year of Master's degree course, and twenty graduates with Specialist's and Master's degree, ten of them had a scientific degree and supervisor's experience at university. The study included two stages. At the first stage, the interview was used to collect information on the main problems of organizing and conducting student-supervisor joint research work. The participants were asked to answer a number of questions and to describe their successful and unsuccessful experience of interaction with the supervisor (for students) and with the student (for supervisors). Next, typical descriptions of interaction with the supervisor (descriptors) were collected and the semantic differential method was used to highlight the main factors that determine the nature of the student-supervisor interaction. The obtained data were processed using the mathematical statistics methods.

At the second stage of the study, the supervisors and the students estimated the proportion of problems encountered at different stages of their collaboration. The data were compared with the data of experts analyzing student-supervisor joint research activity as a research work. The eight experts were Candidates and Doctors of Pedagogical or Psychological Sciences from the Psychology and Pedagogy Institute at Tyumen State University. An interpretation of the causes of the problems arising in student-supervisor joint research activity was given based on a comparison of the assessments of the experts, the students, and the supervisors.

\section{Materials and the results of the research}

The interview, conducted at the first stage of the study, allowed us to identify the typical situations arising in student-supervisor interaction, and their descriptors. As a result of processing the obtained data by the factor analysis method, we identified 4 key factors (the sum of the contributions to the total dispersion of the first four factors is $80.7 \%$ ).

Table 1. The distribution of descriptors by the first factor "supervisor's burden - mutually beneficial cooperation". Factor's weight (35.7\%).

\begin{tabular}{|l|l|}
\hline descriptors & correlation coefficient \\
\hline burden & 0.94 \\
\hline senseless research activity & 0.92 \\
\hline pretence of research activity from both sides & 0.91 \\
\hline written off/purchased research work & 0.88 \\
\hline ease of contact, interaction & -0.70 \\
\hline it is convenient to save time & $-0,78$ \\
\hline my assistant & -0.91 \\
\hline mutually beneficial exchange of methodological and empirical aspects & -0.94 \\
\hline
\end{tabular}


The positive pole of the first factor includes descriptors such as "supervisor's burden", "senseless activity", "pretence of research activity from both sides", "written-off / purchased research work", testifying to the characterization of student-supervisor interaction as a forced process involving a long, laborious activity. Negative descriptors that are "convenient to save time", "my assistants", "and mutually beneficial exchange of methodological and empirical aspects" indicate the importance of cooperation from the point of view of mutual benefit.

Table 2. The distribution of descriptors by the second factor "a source of supervisor's innovative ideas - student's research self-realization». Factor's weight (20. 3\%).

\begin{tabular}{|l|l|}
\hline descriptors & correlation coefficient \\
\hline high joint interest in joint research activity & 0.80 \\
\hline long-term "hatching ideas" & 0.77 \\
\hline innovation & 0.73 \\
\hline running a new idea & 0.70 \\
\hline student's independence & -0.71 \\
\hline student's subjectivity & -0.81 \\
\hline opportunity for the student to prove him/herself & -0.91 \\
\hline
\end{tabular}

The positive pole of the second factor includes such descriptors as "high joint interest in joint research activity", "long-term hatching ideas", "innovation", "running in a new idea". The negative pole includes the descriptors: "student's independence", "student's subjectivity", "opportunity for the student to prove him/herself." The factor contrasts student-supervisor interests in joint research activity. Perhaps this division can be described as "a source of supervisor's innovative ideas - student's research self-realization".

Table 3. The distribution of descriptors by the third factor "a source of additional information useless interaction”. Factor's weight (14.0\%).

\begin{tabular}{|l|l|}
\hline descriptors & correlation coefficient \\
\hline closing the gaps in the supervisor's work & 0.77 \\
\hline supplement to various studies & 0.74 \\
\hline research related to a supervisor's theme & 0.73 \\
\hline $\begin{array}{l}\text { mutually beneficial exchange of methodological and empirical } \\
\text { aspects }\end{array}$ & 0.69 \\
\hline common research interest & 0.68 \\
\hline student's independence in the selection of a theme & -0.54 \\
\hline divergence of research interests & -0.66 \\
\hline opportunity for the student to prove him/herself & -0.72 \\
\hline
\end{tabular}

The positive pole of the third factor includes descriptors: "closing gaps in supervisor's work", "supplement to various studies", "research related to a supervisor's theme", "mutually beneficial exchange of methodological and empirical aspects". The negative pole is represented by the descriptors: "student's independence in the selection of a theme", "divergence of research interests", "opportunity for the student to prove him/herself". In this distribution of descriptors we observe a contrast between the presence and absence of the ability to use student's research work to implement own tasks.

To the positive pole of the fourth factor includes such descriptors as "convenient to collect information / save time", "my assistants", "facilitating scientific work" (probably, this is about the primary collection of information, which the supervisor plans to use in the future). The negative pole includes "showing subjectivity", "student's suggestions", "independent choice of a theme".

Student-supervisor interaction ways in joint research activity. 
According to the results of the interviews, we underlined the student-supervisor interaction ways that reduce students' motivation for a creative approach to writing a piece of research work: "student's research work is a source of primary information processing", "student's research work is a source of additional information", "student's research work is a source of innovative ideas for the supervisor", 'student's research work is supervisor's burden".

Table 4. The distribution of descriptors by the fourth factor "a source of primary information processing for the supervisor - scientific work for himself/herself. Factor's weight (10.7\%).

\begin{tabular}{|l|l|}
\hline descriptors & correlation coefficient \\
\hline It is convenient to collect information/to save time & 0.86 \\
\hline my assistants & 0.79 \\
\hline facilitating scientific work & 0.77 \\
\hline 'sift' information & 0.76 \\
\hline searching for new literature & 0.74 \\
\hline showing subjectivity & -0.52 \\
\hline student's suggestions & -0.67 \\
\hline independent choice of a theme & -0.89 \\
\hline
\end{tabular}

"Student's research work is a source of primary information processing." The supervisor, preparing his/her own candidate or doctoral thesis, makes students search for materials and write reviews, essays, and articles in the logic of his/her scientific work that is being prepared, e.g. themes offered to students coincide with the paragraphs of the supervisor's future research work.

"Student's research work is a source of additional information." The supervisor developing his/her theme is interested in obtaining new data and ideas. This is realized by either directly formulating a theme of student's research work, or modifying a subject and an idea of research proposed by the student to his/her own research theme. The reasons for necessary correction are most often referred to as: "...there is no base for such a research theme or the subject does not fall within the boundaries of the scientific discipline", etc. Usually, in such a situation, the student has not have his/her own experience in writing serious research work yet, therefore, he/she does not always notice how the theme or idea takes on a completely new character, and if it does, the student cannot always defend his/her position.

"Student's research work is a source of innovative ideas for the supervisor." The supervisor, helping the student prepare research work, involves in the theme and begins to put forward his/her own ideas. The supervisor adds new data to student's research work, corrects the text, offers his/her own understanding of the structure, logic of the text, conclusions and etc. Gradually, the student's text turns into the supervisor's text.

"Student's research work is supervisor's burden" (64\% of participants note this factor in professional environment). This kind of situation in modern high school is not so rare. For supervisors, it is quite a widespread practice of supervising more than fifteen (sometimes more than twenty-five) students who are at different stages of preparing research work of various levels, e. g. from the first year research work to the final year research work. A variety of training programs, research bases, experimental transformations make extremely high demands on the level of scientific support provided by the supervisor. Not having time to deeply understand a variety of students' research themes, supervisors are often forced to take three well-known "formalized" roles. In the first case of joint research activity, the supervisor meets with students, and gives general instructions: "Start writing something on this topic", "When you write, bring it, I will read it, and then we will discuss it." And later: "I read your text ... the idea is interesting, but there is no concept ...; you have different pages number in the first and second paragraph, correct ...; the conclusion on the chapter is 
not clear...". In the second case of joint research activity, the supervisor monitors the general methodology, without going into the specifics of particular research work: "We need to justify relevance, designate an object, subject, goals, objectives ...", "Find and read manuals on writing scientific papers". "Find thesis work related to you theme and read it". In the third case of joint research activity, the supervisor makes numerous small, often unprincipled changes in student's research work, many of which contradict one another from time to time. The text of research work does not take on a specific outline for a long period of time; the student does not receive answers to key questions, remaining captive to numerous edits.

Student-supervisor interaction problems in joint research activity.

At the second stage, the questionnaire established the main problems in studentsupervisor interaction in joint research activity. Using experts' survey, we identified three categories of research work quality for each of the selected criteria: (1) a high quality level: compliance with design requirements for scientific research, a meaningful content, verified methodology; (2) an average quality level: compliance with design requirements for scientific research, a formal information presentation, minor violations in methodology; (3) a low quality level: violations in design requirements for scientific research, information omissions, gross violations in methodology. The data obtained are shown in table 5.

Table 5. Correlation of student-supervisor interaction problems in joint research activity.

\begin{tabular}{|l|l|l|l|l|}
\hline № & $\begin{array}{l}\text { Elements of research writing } \\
\text { causing problems in student- } \\
\text { supervisor interaction }\end{array}$ & $\begin{array}{l}\text { A problem } \\
\text { reported by the } \\
\text { supervisor (\%) }\end{array}$ & $\begin{array}{l}\text { A problem } \\
\text { reported by the } \\
\text { student (\%) }\end{array}$ & $\begin{array}{l}\text { Student's } \\
\text { research work } \\
\text { considered by } \\
\text { the experts as } \\
\text { low (\%) }\end{array}$ \\
\hline 1 & research theme definition & $47 \%$ & $31 \%$ & $32 \%$ \\
\hline 2 & $\begin{array}{l}\text { research subject and object } \\
\text { definition }\end{array}$ & $16 \%$ & $10 \%$ & $35 \%$ \\
\hline 3 & hypothesizing & $21 \%$ & $64 \%$ & $26 \%$ \\
\hline 4 & problematizing & $13 \%$ & $79 \%$ & $42 \%$ \\
\hline 5 & scientific literature review & $2 \%$ & $1 \%$ & $29 \%$ \\
\hline 6 & research methods selection & $3 \%$ & $44 \%$ & $2 \%$ \\
\hline 7 & empirical data collection & $5 \%$ & $10 \%$ & $1 \%$ \\
\hline 8 & results interpretation & $7 \%$ & $34 \%$ & $33 \%$ \\
\hline
\end{tabular}

The uneven distribution of the assessment of student-supervisor problems suggests that a problem will be solved by one side (it is more often a supervisor) in the process of joint research activity. In addition, there are situations that are assessed as problem-free by both supervisors and students, while an expert assessment indicates a poor quality of elaboration of this aspect. Probably, these data indicate a low level of awareness of the complexity of research activity elements, both on the part of supervisors and students. For example, a problem "scientific literature review" is traditionally perceived as a compilation: the supervisor does not imagine what problems the student may encounter, while the student initially plans to borrow data/facts for a theoretical chapter in a very formal way on the Internet, without delving into the logic of his/her research work.

\section{Conclusions}

The conducted research allows us to conclude that the process of interaction between the student and the supervisor is perceived by a significant part of the participants in the educational process as forced, involving long, laborious work. At the same time, the participants perceive the interaction as a mutually beneficial process. The study also shows 
the presence of opposition between the interests of the supervisor and the student in the process of joint research activities. It has been established that the main difficulties in the interaction of a supervisor and a student in scientific research consist of determining the topic, subject, object of research, and hypothesis. The research has identified the variants of the relationship "supervisor-student" that reduce the motivation of students to be creative in writing research papers such as student research work - a source of primary information processing, a source of additional information, a source of innovative ideas of a supervisor, a burden for a supervisor.

Leaving behind the moral and ethical aspect of supervisor's behavior, it should be noted that joint research activity can be very useful for students, but only if interaction is a longterm research work process in a scientific team, which gradually allows students to collect basic data, facts for research work. In our opinion, this is possible only under conditions of practice-oriented scientific team (ideally a scientific school), in which supervisors constantly research urgent problems of modern science and practice. In other words, it is possible under conditions in which the key labor function of university scientists is to conduct research, rather than teaching. It should be noted that, according to almost all respondents (97\%), one of the most important factors "destroying research aura" is a periodic thesis proposal defense, during which students summarize the achieved results, and propose an actual variant of scientific work. It is very indicative that none of the respondents perceived the periodic thesis proposal defense procedure as a kind of training, preparation, rehearsal of a real defense, but only as an event, the key content of which was criticism of student's speech or research work text.

An attempt to find a way out of this situation should force supervisors to honestly take one of two positions: either the university continues to try to impart a "research" character to students' work, which as a matter of fact, are not considered as research work or either the university clearly defines student's research work that demonstrate a formal correspondence to the logic of research work (abstract, semester long research work, Bachelor's degree research work, Master's degree research work, and an independent piece of student's scientific work). It brings to mind awarding academic degrees during the Soviet Union: the so-called "in terms of the totality of work", in which a tutor did not write a candidate's or a doctor's, but presented the results of his/her professional work (articles, methodological developments, projects, books and etc.). Under modern conditions of higher education modernization, it is possible to add evidence of student's participation in specialized events (for example, competitions) or projects, in scientific research of a particular scientific group / laboratory, in targeted thematic projects (Russian Foundation for basic research, Initiatives, etc), publications in high-ranking journals, or references to research, work experience. If desired, the list of these units can be approved at the university level. With this approach, students have a choice: to be included in research creative activity, or to confine themselves to writing a compilation. In this regard, pedagogy and psychology provide the broadest possibilities in describing diverse historical and modern experience of psychological and pedagogical activity in a socially oriented sphere of society.

The Research is executed with assistance of the Russian Federal Property Fund within the scientific project No. 18-013-00268 A "Formation of research competences of students of the system of multilevel university psychology and pedagogical education and professional development of pedagogical shots". 


\section{References}

1. B.G. Barnett, R. Muth, Using action-research strategies and cohort structures to ensure research competence for practitioner-scholar leaders, Journal of Research onLeadership Education, 3 (1), 1-42, doi:10.1177/194277510800300101 (2008)

2. E. Gullbekk, K. Byström, Becoming a scholar by publication - $\mathrm{PhD}$ students citing in interdisciplinary argumentation, Journal of Documentation, 75 (2), 247-269. doi: 10.1108/JD-06-2018-0101, (2019)

3. C.P. Casanave, Taking risks: A case study of three doctoral students writing qualitative dissertations at an American university in Japan, Journal of second language writing, 19, 1-16, doi:10.1016/j.jslw.2009.12.002 (2010)

4. R.H. Cantwell, J.J. Scevak, S. Bourke, A. Halbrook, Identifying individual differencesamong doctoral candidates: A framework for understanding problematic candidature, Int. J. of Educational Research, 53, 68-78, doi: 10.1016/j.ijer.2012.02.001 (2012)

5. Y. Li, I have no time to find out where the sentences came from; I just rebuild them: A biochemistry professor eliminating novices' textual borrowing, Journal of second language writing, 21 (1), 59-70, doi: 10.1016/j.jslw.2012.01.001 (2012)

6. C.J. Lassig, L.H. Dillon, M.D. Carmel, Student or scholar? Transforming identities through a research writing group, Studies in continuing education, 35 (3), 299-314, doi: 10.1080/0158037X.2012.746226 (2013)

7. I. Lee, Becoming a writing teacher: Using "identity" as an analytic lens to understand EFL writing teachers' development, Journal of second language writing, 22 (3), 330-345, doi: 10.3138/cmlr.599 (2013)

8. M. Fujioka, L2 student-US professor interactions through disciplinary writing assignments: An activity theory perspective, Journal of second language writing, 25, 40-58, doi:10.1016/j.jslw.2014.05.004 (2014)

9. C.H. Guerin, I. Green, Supervision pedagogies: narratives from the field, Teaching in higher education, 20 (1): 107-118, doi: 10.1080/13562517.2014.957271(2015)

10. J. Morton, N. Storch, C. Thompson, What our students tell us: Perceptions of three multilingual students on their academic writing in first year, Journal of second language writing, 30, 1-13, doi: 10.1016/j.jslw.2015.06.007 (2015)

11. H.L. Santos, C. Cechinel, The final year project supervision in online distance learning: assessing students and faculty perceptions about communication tools. Behaviour \& Information technology, 38 (1), 65-84, doi: 10.1080/0144929X.2018.1514423 (2019)

12. A. Helmke, Forschung zur Lernwirksamkeit des Lehrerhandelns. Handbuch der Forschung zum Lehrerberuf. Münster (Waxmann, 2014)

13. Z.K. Ravari, K.E. Tan, A qualitative investigation of strategies and experiences of non-native students writing master's theses, Journal of applied research in higher education, 11 (2), 310-324, doi: 10.1108/JARHE-07-2018-0120 (2019)

14. J. Wei, S. Carter, D. Laurs, Handling the loss of innocence: first-time exchange of writing and feedback in doctoral supervision, Higher education research and development, 38 (1), 157-169, doi: 10.1080/07294360.2018.1541074 (2019)

15. Yu.V. Solyanikov, Organization of research activities in the master's program of the University (Saint-Petersburg. Research on modern pedagogical problems, 2001) 
16. A.F. Zakirova, The methodological unit of scientific research in terms of conceptualization of pedagogical knowledge. The Education and science journal, 10, 4-19, doi.10.17853/1994-5639-2015-10-4-19 (2015)

17. A.N. Gebekova, Research work of students in the framework of the integration of science and education and the organization of research activities in higher education. Education and training: theory, methodology and practice (2016).

18. M.N. Krylova, Interaction of subjects of research as a factor in the self-realization of the personality of the teacher and student. Scientific and methodical electronic journal "Concept", 40, 24-29, doi: 10.24411/2304-120X-2019-15025 (2016)

19. V.V. Frolov, Student-supervisor joint research activity: experience and prospects of interaction, doi: 10.24411/2304-120X-2019-13044 (Pskov, 2017)

20. E.G. Koshkina, Research competence of students: its formation within the framework of project and research activities in and out of the higher school. Public education. Pedagogy 1, 52-58, doi: 10.18720/HUM/ISSN 2227-8591.27.8 (Publishing House Stavrolit, 2018)

21. I.B. Aminov, N.A. Sharapova, Use of information technology in the organization of research work of students, Young Scientist 3, 769-771 (2016)

22. V.O. Topolsky, Use of information and communication technologies in preparing students of a pedagogical university for participation in scientific and practical conferences, competitions. Young Scientist, 10, 537-539 (2013)

23. I.G. Zakharova, Use of electronic resources in the educational and research activities of university students. Bulletin of the Tyumen State University. Socioeconomic and legal studies, 9, 33-37 (2011)

24. Yu.P. Gospodarik, Use of Internet technologies in the organization of research work. Higher education in Russia, 2, 115-121 (2012)

25. E.G. Belyakova, I.G. Zakharova, Interaction of university students with educational content in the conditions of information educational environment. The Education and science journal, 21(3), 77-105, doi:10.17853/1994-5639-2019-3-77-105 (2019)

26. T.A. Strokova, Building research competence of $\mathrm{PhD}$ students: an analysis of experience of a PhD school. The Education and science journal, 20 (10), 9-30, doi: 10.17853/1994-5639-2018-10-9-30 (2018)

27. E.I. Arzhilovskaya, A.V. Chumakova, The role of scientific research in the activities of a new generation university teacher. European journal of education and applied psychology, 2, 4-7 (2016)

28. S.A. Khojaliev, Place and role of interactive technologies in the process of forming the professional competence of university graduates. Pedagogy of higher education, $\mathbf{3}$ 45-48 (2015)

29. O.S. Andreeva, O.A. Selivanova, I.V. Vasilieva, Comprehensive Diagnosis of Components of Pedagogical Students' Research Competency. The Education and science journal, 21 (1), 37-58, doi: 10.17853/1994-5639-2019-1-37-58 (2019) 